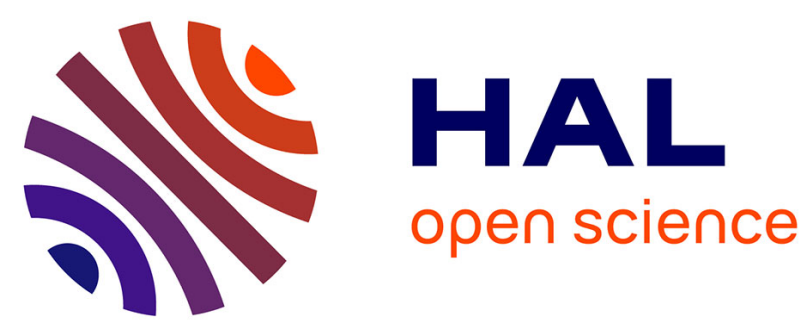

\title{
ANALYTICAL NON-RELATIVISTIC SCF-HARTREE-FOCK WAVE FUNCTIONS FOR THE GROUND STATE AND FOR EXCITED STATES OF In AND TI IONS
}

R. Bauer, K. Differt, L. Schwan

\section{To cite this version:}

R. Bauer, K. Differt, L. Schwan. ANALYTICAL NON-RELATIVISTIC SCF-HARTREE-FOCK WAVE FUNCTIONS FOR THE GROUND STATE AND FOR EXCITED STATES OF In AND Tl IONS. Journal de Physique Colloques, 1976, 37 (C7), pp.C7-177-C7-180. 10.1051/jphyscol:1976740 . jpa-00216897

\section{HAL Id: jpa-00216897 https://hal.science/jpa-00216897}

Submitted on 1 Jan 1976

HAL is a multi-disciplinary open access archive for the deposit and dissemination of scientific research documents, whether they are published or not. The documents may come from teaching and research institutions in France or abroad, or from public or private research centers.
L'archive ouverte pluridisciplinaire HAL, est destinée au dépôt et à la diffusion de documents scientifiques de niveau recherche, publiés ou non, émanant des établissements d'enseignement et de recherche français ou étrangers, des laboratoires publics ou privés. 


\title{
ANALYTICAL NON-RELATIVISTIC SCF-HARTREE-FOCK WAVE FUNCTIONS FOR THE GROUND STATE AND FOR EXCITED STATES OF In AND TI IONS
}

\author{
R. BAUER, K. DIFFERT \\ Institut für Physik am Max-Planck-Institut für Metallforschung, Stuttgart, und Institut \\ für Theoretische und Angewandte Physik der Universität Stuttgart, Pfaffenwaldring 57/VI, \\ D-7000 Stuttgart 80, F. R. G.
}

and

\section{SCHWAN}

Physikalisches Institut, Teilinstitut 2, der Universität Stuttgart, F. R. G.

\begin{abstract}
Résumé. - Des solutions Hartree-Fock non relativistes en forme de développements analytiques utilisant des fonctions orbitales du type Slater ont été obtenues pour l'état fondamental de In $^{+}, \operatorname{In}^{++}$, $\mathrm{Tl}^{+}, \mathrm{Tl}^{++}$et pour des états excités de $\mathrm{In}^{+}$. Les fonctions d'onde et les intégrales de recouvrement des fonctions orbitales extérieures de ces métaux avec l'ion $\mathrm{Cl}^{-}$sont présentées. Dans l'approximation non relativiste les ions de $\mathrm{Tl}$ possèdent essentiellement la même taille et les mêmes intégrales de recouvrement que les ions de In. Des corrections relativistes ont été estimées et sont discutées; pour $\mathrm{Tl}^{+}$ces corrections sont à peu près trois fois plus grandes que pour $\mathrm{In}^{+}$. Dans le cas des centres de défauts de substitution d'ions métalliques monovalents dans $\mathrm{KCl}$ les déplacements des plus proches voisins sont estimés pour l'état fondamental et pour l'état excité. Tous ces déplacements se révèlent positifs, indiquant un déplacement des voisins radialement vers l'extérieur.

Abstract. - Non-relativistic Hartree-Fock solutions for the ground state of $\mathrm{In}^{+}, \mathrm{In}^{++}, \mathrm{Tl}^{++}, \mathrm{Tl}^{++}$ and for excited states of $\mathrm{In}^{+}$have been obtained in the form of analytical expansions in Slater-type orbitals. The wave functions and overlap integrals of the outer metal orbitals with the chlorine ion are presented. In the non-relativistic approximation the $\mathrm{Tl}$ ions have essentially the same size and the same overlap integrals as the In ions. Relativistic corrections are estimated and discussed ; for $\mathrm{Tl}^{+}$ they are almost three times larger than for $\mathrm{In}^{+}$. The nearest neighbour displacements for substitutional defect centres of the monovalent ions in $\mathrm{KCl}$ are derived for the ground state and for an excited state. All displacements come out as positive, indicating an outward radial displacement of the neighbours.
\end{abstract}

1. Introduction. - In an attempt to improve the understanding of heavy metal ion centers in ionic solids, we have calculated non-relativistic HartreeFock (HF) wave functions for the ground states of $\mathrm{In}^{+}, \mathrm{In}^{++}, \mathrm{Tl}^{+}, \mathrm{Tl}^{++}$, and for several excited states of $\mathrm{In}^{+}$and $\mathrm{In}^{\circ}$, using Roothaan's method $[1,2]$ of analytical expansion of the orbital wave functions in Slater-type orbitals (STOs). In this representation, the orbitals are described by a limited number of parameters and may hence be easily communicated and are readily applicable in molecular or solid state problems.

In this note we present atomic Hartree-Fock data and some overlap integrals of the substitutional metal ions with neighbouring ions of the crystal environment in $\mathrm{KCl}$. We then discuss corrections due to relativistic effects. Finally the data are used to estimate the sign and magnitude of the radial displacements of the nearest-neighbours (nn) of the defect centers.
2. Results of the Hartree-Fock calculations. - The STO basis, being similar to that used by Synek et al. [3] for $\mathrm{Nd}^{3+}$, may be characterized as an extended double zeta basis set yielding the accuracy of the near HF limit. The basis set comprises 30 STOs for the cases of $\mathrm{Tl}^{+}$and $\mathrm{Tl}^{++}$. The program handles the full nonlocal exchange interaction. Further details on the numerical calculations and the accuracy of the results will be given elsewhere.

Figure 1 presents the probability amplitude of the $\mathrm{Tl}^{+} 6 \mathrm{~s}$ orbital in the $(x, y, o)$ plane in a vertical section through the nucleus. It shows the five radial nodes of a $6 \mathrm{~s}$ function and the rapid oscillations near the nucleus.

In Table I, the mean orbital radii $\langle r\rangle$ for the outer shell of the ionic ground states are given, and the overlap integrals between the substitutional metal ions and a n.n. chlorine ion in $\mathrm{KCl}$ are listed.

The following figures show the radial part of the 


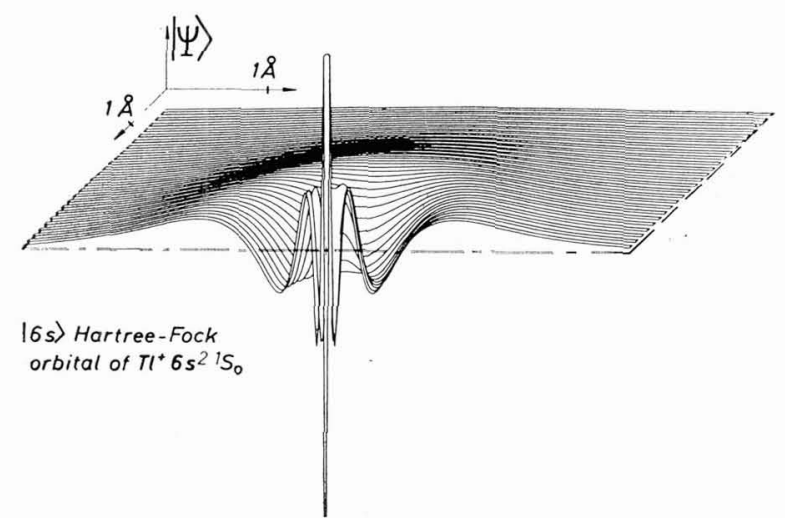

FIG. 1. - Probability amplitude of the $\mathrm{Tl}^{+}$6s $\mathrm{HF}$ orbital in the $(x, y, 0)$ plane in a vertical section through the nucleus. The sharp negative central peak describes the finite amplitude of the s state at the nucleus.

metal orbitals and their overlap with the nn chlorine $3 s$ and $3 p$ orbitals. The nuclei are located in the two crossing points of the coordinate axes. The radial functions are multiplied by the radial distance $r$ from their respective nucleus. The even and odd parities are indicated for the $\mathrm{Cl}^{-} 3 \mathrm{~s}$ and $3 \mathrm{p}$ orbitals, respectively.

Figure 2 compares the $5 \mathrm{~s}$ and $4 \mathrm{~d}$ orbitals of $\mathrm{In}^{+}$ (dashed lines) with the outer $3 \mathrm{~s}$ and $3 \mathrm{p}$ shells of $\mathrm{K}^{+}$ representing the situation in the perfect lattice. It is seen that the $\mathrm{In}^{+}$ion is considerably larger than $\mathrm{K}^{+}$, forming much larger overlap integrals (cf. Table I), though as the $\mathrm{In}^{+}$overlap does not depend so strongly on the interatomic distance.

Figure 3 shows the $6 \mathrm{~s}, 5 \mathrm{~d}$ and $4 \mathrm{f}$ orbitals of $\mathrm{Tl}^{+}$ (full lines) and $\mathrm{Tl}^{++}$(dashed lines). The HF radial extensions of the $\mathrm{Tl}$ ions are nearly the same as those of the In ions, their mean radii differing but by $3 \%$.

The reduction of the occupation number of the outer $\mathrm{s}$ shell from two to one in going from $\mathrm{Tl}^{+} 6 \mathrm{~s}^{2}$ to $\mathrm{Tl}^{++}$ $6 \mathrm{~s}^{1}$ reduces its mean radius $\langle r\rangle$ by only $7 \%$ and has a quite small effect on the shape of the $5 \mathrm{~d}$ shell. The $6 \mathrm{~s}$ mean overlap integrals differ by 17 per cent.

In Figure 4 the outer orbitals of several excited states of $\mathrm{In}^{+}$are collected. The $5 \mathrm{p}$ state lying only $5 \mathrm{eV}$ above the ground state is somewhat more extended than the

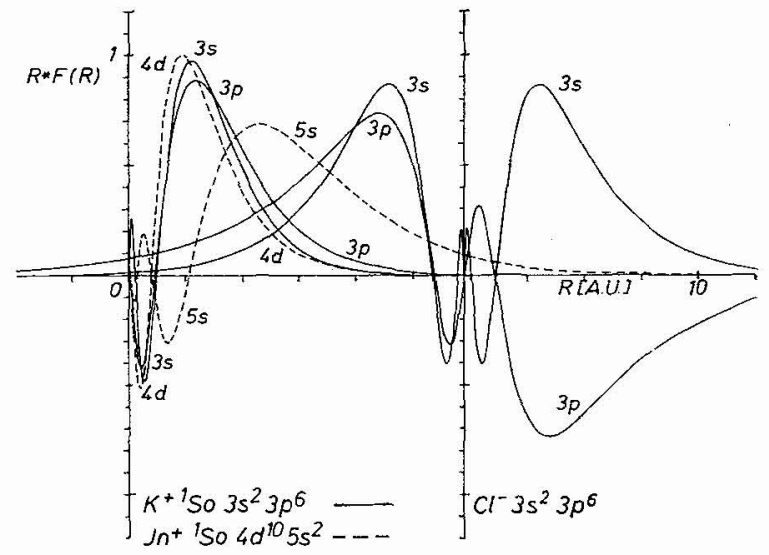

FIG. 2. - Radial part of HF orbitals of $\mathrm{Cl}^{-}$and of the ground states of $\mathrm{K}^{+}{ }^{1} \mathrm{~S}_{0}$ (solid lines) and $\mathrm{In}^{+}{ }^{1} \mathrm{~S}_{0}$ (dashed lines). The centres of the ions are located at the crossing points of the coordinate axes and are separated by the interatomic distance in $\mathrm{KCl}, r_{0}=3.12 \AA=5.896$ a. u.

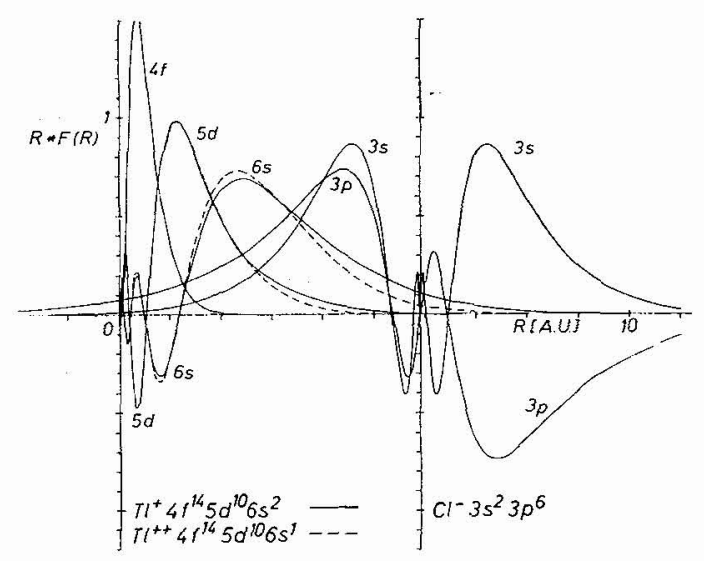

FIG. 3. - Radial part of HF orbitals of $\mathrm{Cl}^{-}$and of the ground states of $\mathrm{Tl}^{+}{ }^{1} \mathrm{~S}_{0}$ (solid lines) and $\mathrm{Tl}^{++}{ }^{2} \mathrm{~S}_{1 / 2}$ (dashed lines).

The ions are separated by the interatomic distance in $\mathrm{KCl}$.

5 s orbital, forming quite large overlap integrals of the order of 0.2 to 0.3 . The $5 \mathrm{~d}$ and $6 \mathrm{~s}$ states lying $10 \mathrm{eV}$ above the ground state are widely extended having. their maxima near the nn nucleus. Hence the $3 p_{\sigma}>$ overlap is very small due to the odd parity of the $3 p$. function, while the $\mid 3 p_{\pi}>$ and $\mid 3 s>$ overlaps are of the order of 0.4. The excited state orbitals of neutral

TABLE I

Mean orbital radius $\langle r\rangle$ and overlap integrals for the outer orbital of ionic ground states of $\mathrm{K}$, In, and $\mathrm{Tl}$. The overlap integrals are calculated for the nearest-neighbour distance in $\mathrm{KCl}, r_{0}=3.12 \AA$

\begin{tabular}{|c|c|c|c|c|c|}
\hline $\begin{array}{l}\text { Atomic } \\
\text { State } \\
\text { Orbital nl }\end{array}$ & $\begin{array}{c}\mathrm{K}^{+} \mathrm{Ar} \\
{ }^{1} \mathrm{~S}_{0} \\
{ }^{3 \mathrm{p}}\end{array}$ & $\begin{array}{c}\mathrm{In}^{+} 5 \mathrm{~s}^{2} \\
{ }^{1} \mathrm{~S}_{0} \\
5 s\end{array}$ & $\begin{array}{c}\mathrm{In}^{++} 5 \mathrm{~s}^{1} \\
{ }^{2} \mathrm{~S}_{1 / 2} \\
5 \mathrm{~s}\end{array}$ & $\begin{array}{c}\mathrm{Tl}^{+} 6 \mathrm{~s}^{2} \\
{ }^{1} \mathrm{~S}_{0} \\
6 \mathrm{~s}\end{array}$ & $\begin{array}{c}\mathrm{Tl}^{++} 6 \mathrm{~s}^{2} \\
{ }^{2} \mathrm{~S}_{1 / 2} \\
6 \mathrm{~s}\end{array}$ \\
\hline$<r \bar{r}[\AA]$ & $0 . \overline{7574}$ & $1 . \overline{429}$ & $1 . \overline{325}$ & $1 . \overline{486}$ & $1 . \overline{382}$ \\
\hline$<\mathrm{nl}_{\sigma}\left|\mathrm{Cl}_{3 \mathrm{p} \sigma}^{-}\right\rangle$ & 0.0705 & 0.1825 & 0.1628 & 0.1875 & 0.1673 \\
\hline$\left\langle\mathrm{nl}_{\sigma} \mid \mathrm{Cl}_{3 \mathrm{~s}}^{-}\right\rangle$ & 0.0257 & 0.0855 & 0.0624 & 0.0920 & 0.0649 \\
\hline
\end{tabular}




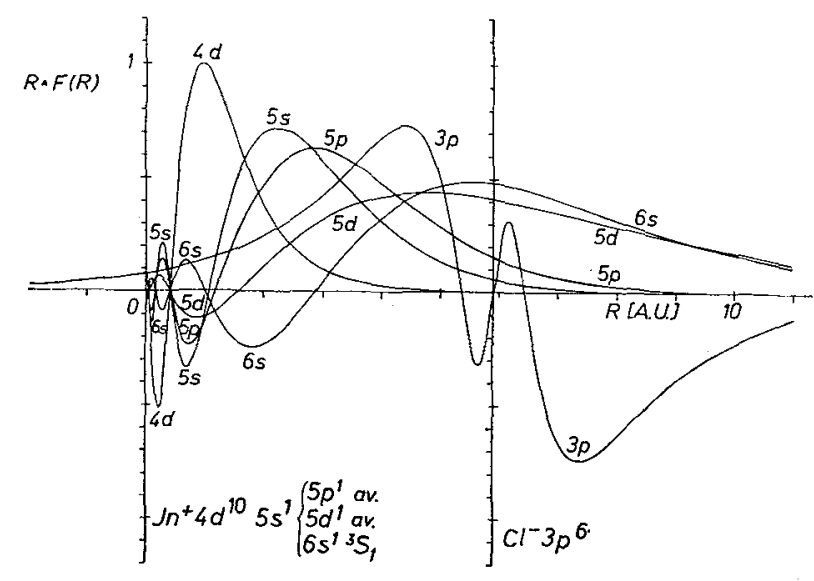

FIG. 4. - Radial part of HF orbitals of excited states of In $^{+}$ and their overlap with the $\mathrm{Cl}^{-} 3 \mathrm{p}$ orbital in $\mathrm{KCl}$. The shown $5 s$ function belongs to the states $5 s^{1} 5 d^{1}$ and $5 s^{1} 6 s^{1}$.

$\mathrm{In}^{0}$ not shown here are even more extended, their mean radii being 20 per cent larger than those of the corresponding states of $\mathrm{In}^{+}$.

3. Relativistic corrections. - The relativistic effects due to the high electron velocities in the inner $s_{1 / 2}$ and $\mathrm{p}_{1 / 2}$ shells (jj coupling) of large $Z$ atoms cause a spatial tightening and an increase of the binding of these orbitals. This effect is transfered via the orthogonality constraints of the radial parts of the orbitals to the outer $s_{1 / 2}$ and $p_{1 / 2}$ electrons, whereas in a compensating reaction the $\mathrm{p}_{3 / 2}, \mathrm{~d}$, and $\mathrm{f}$ shell electrons loosen slightly and extend radially $[4,5]$.

The relativistic corrections for several atomic observables of the HF ground states of all neutral atoms are given in [5]; from these data and from a comparison between the calculated HF ionization energies and the optical ionization potentials the corrections for the ions may be found.

\section{TABLE II}

Relativistic corrections for the orbital energy $\varepsilon$, the mean radius $\langle r\rangle$, and the mean nearest-neighbour overlap $\bar{S}\left(\mathrm{Me}^{+} \mid \mathrm{Cl}^{-}\right)$in $\mathrm{KCl}$, in per cent of the Hartree-Fock values

$\begin{array}{cccc}\text { Per cent } & \Delta \varepsilon & \Delta<r> & \Delta \bar{S}\left(\mathrm{Me}^{+} \mid \mathrm{Cl}^{-}\right) \\ \overline{\mathrm{Ga}^{+}} 4 \mathrm{~s}^{2} & \overline{2.4} & -1.5 & -3.5 \\ \mathrm{In}^{+} 5 \mathrm{~s}^{2} & 7.0 & -4 & -9 \\ \mathrm{Tl}^{+} 6 \mathrm{~s}^{2} & 17.0 & -11 & -24\end{array}$

Table II shows the relativistic corrections obtained for the orbital eigenvalue $\varepsilon$, the mean orbital radius $\langle r\rangle$, and an average of the overlap integrals with the $\mathrm{nn} \mathrm{Cl}^{-}$ion in $\mathrm{KCl}$. The corrections for the over-

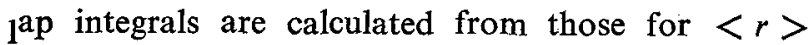

using the relation between the change in $\langle r\rangle$ and the change in the interatomic overlap found by comparing the data for the monovalent and divalent ions given in Table I.

It is seen that the corrections for $\mathrm{Tl}(Z=81)$ are almost three times larger than those for In $(Z=49)$ and seven times larger than those for $\mathrm{Ga}(Z=31)$. In the non-relativistic approximation, In and $\mathrm{Tl}$ are almost identical in all their properties, cf. table I. The relativistic effects yield a much stronger additional binding for the Tl $6 \mathrm{~s}$ shell than for the In $5 \mathrm{~s}$ shell ; they turn $\mathrm{Tl}$ into a monovalent metal forming $\mathrm{CsCl}$ type ionic solids, while In stays trivalent like $\mathrm{Ga}$ and $\mathrm{Al}$ and forms preferentially covalent bonds. The $\mathrm{Tl}$ ions eventually have a smaller size than the In ions, the ionic radius and the mean nn overlap of $\mathrm{Tl}^{+}$ being smaller by 6 and 15 per cent, respectively, than those of $\mathrm{In}^{+}$.

4. The equilibrium configuration of In and $T l$ centres in $\mathrm{KCl}$. - The equilibrium displacements in the lattice about a substitutional isovalent metal ion centre may be obtained to a first approximation by contrasting the short range forces of the substituted cation of the perfect lattice $\left(\mathrm{K}^{+}\right)$with those of the substituent cation $\left(\mathrm{In}^{+}\right.$or $\left.\mathrm{Tl}^{+}\right)$. In the framework of the Löwdin. Approximation [6, 7] of the HF scheme for ionic solids, the short range interaction is roughly proportional to the square of the interatomic overlap, and the forces in addition depend on the steepness of its variation with the interatomic distance. From our overlap data and from an estimate of the Van der Waals strengths being considerably larger for $\mathrm{In}^{+}$ and especially for $\mathrm{Tl}^{+}$than for $\mathrm{K}^{+}$representing the perfect lattice, we obtain the $\mathrm{nn}$ displacements of substitutional centres given in table III. The displacements being related to the perfect lattice positions are all positive, indicating a radial outward shift both for the ground states and for the excited states of the centres. The vibronic interaction with the lattice has not yet been taken into account on this stage of approximation.

\section{TABLE III}

Equilibrium displacements of the nearest neighbours of substitutional $\mathrm{In}^{+}$and $\mathrm{Tl}^{+}$centres in $\mathrm{KCl}$. The displacements refer to the perfect lattice positions and are given in per cent of the $n$ distance, $r_{0}=3.12 \AA$

$$
\begin{aligned}
& \mathrm{K}^{+} \quad \mathrm{In}^{+} \quad \mathrm{Tl}^{+} \quad \mathrm{In}^{+} 5 \mathrm{~s}^{1} 5 \mathrm{p}^{1} \quad \mathrm{Tl}^{+} 6 \mathrm{~s}^{1} 6 \mathrm{p}^{1} \\
& \begin{array}{ll}
\text { Radial ground states excited states } \\
\text { displ. }
\end{array} \\
& \begin{array}{llllllll}
\stackrel{\text { displ. }}{-} & \overline{0} & \overline{6.5} & \overline{4.0} & \frac{\sigma}{9.5} & \frac{\pi}{2.5} & \frac{\sigma}{6.0} & \frac{\pi}{1.7}
\end{array}
\end{aligned}
$$

The relaxation of the excited states $n s^{1} n p^{1}$ consists of an additional outward movement of the two $\sigma$ neighbours and an inward relaxation of the four $\pi$ 
neighbours, leading to a strong tetragonal distortion of the lattice. Due to the stronger relativistic effects for $\mathrm{Tl}$ causing a radial contraction of the $\mathrm{s}_{1 / 2}$ and $\mathrm{p}_{1 / 2}$ orbitals, the displacements associated with the $\mathrm{Tl}$ centres are smaller than those of the In centres.

Further details on the derivation of the lattice distortions will be given elsewhere. A more thorough treatment of the short range forces and the inclusion of other interactions not yet considered, such as the polarization energy originating from the fields of deformation dipoles, will probably not alter the relative sizes and the sign of the reported displacements.

Note added in proof. - A detailed account of the subject of this note is given by the same authors in Semiconductors and Insulators 1 (1977).

Acknowledgments. - This work is part of the program of the «Sonderforschungsbereich 67 : Defektstrukturen ».

\section{References}

[1] Roothaan, C. C. J., Rev.Mod. Phys. 23 (1951) 69.

[2] Roothaan, C. C. J., Bagus, P. S., in Methods of Computational Physics, B. Alder et al. (Pergamon) 1963, Vol. 2.

[3] Synek, M., Grossgut, P., Phys. Rev. A 1 (1970) 1.

[4] Desclaux, J. P., I. J. Quant. Chem. 6 (1972) 25.
[5] Desclaux, J. P., Atomic Data and Nuclear Data Tables 12 (1973) 312

[6] Abarenkov, I. V., Antonova, I. M., Phys. Status Solidi 38 (1970) 783.

[7] BAuER, R., Phys. Status Solidi (b) 50 (1972) 225 ; BAuER, R., J. Nonmetals 1 (1973) 257.

\section{DISCUSSION}

R. J. Friauf, - The effect of the Madelung potential and the neighboring ions on the $\mathrm{Cl}^{-}$wave functions is by no means negligible in $\mathrm{KCl}$. The overlap integrals for $\mathrm{K}^{+} \mathrm{Cl}^{-}$, and even more so for $\mathrm{Cl}^{-} \mathrm{Cl}^{-}$, are reduced by factors of 2 to 5 .

R. BAUER. - The large nn $\mathrm{Me}^{+}-\mathrm{Cl}^{-}$overlaps are not affected much by a reordering of the anion $p$ orbital ; the electrons in the anion orbital have no great chance to escape from overlapping with the extended cation s orbitals. Moreover, if the magnitude of the overlap is decreased by reordering, the steepness of its dependence on the interatomic dis- tance is increased, thus compensating for a change in the force and essentially in the force constants.

A. LAforgue. - How do you calculate the relativistic term ?

R. BAUER. - We correct our self-consistent Hartree-Fock data for the relativistic effects. The corrections are obtained from the ratios between the DiracFock data and the Hartree-Fock data for the neutral atom ground state given in ref. [5]. These corrections are scaled to the ionic ones using the corrections of optical data. Details of this procedure will be published in Semiconductors and Insulators 1 (1977). 